\title{
0 Concerto para Clarineta, Op.57 de Carl Nielsen: contexto, análises e interpretações
}

\author{
Vinicius de Sousa Fraga (UFBA, Salvador, BA) \\ vinicius.clar@gmail.com
}

Resumo: Composto em 1928, o Concerto para Clarineta, Op.57, de Carl Nielsen (1865-1931) tornou-se uma obra fundamental na literatura da clarineta no século XX. A presente pesquisa procura discutir algumas de suas questões de performance através de uma contextualização da época em que foi escrito, com ênfase nos aspectos relevantes sobre 0 compositor e a produção da obra. São observadas as divergências entre a edição da Samfundet e os originais manuscritos. Por meio de uma análise da obra, busca-se discutir sua recepção inicial e seu papel na literatura da clarineta.

Palavras-chave: Carl Nielsen; concerto para clarineta; análise e interpretação musical.

\section{Carl Nielsen's Clarinet Concerto, Op.57: context, analysis and performance}

Abstract: Composed in 1928, Carl Nielsen's Clarinet Concerto, Op.57 became a fundamental work in the twentiethcentury clarinet literature. This study discusses some of the work's performance aspects by means of examining its context related to its composer and compositional procedures. The discrepancies between the Sanfundet edition and the composer's manuscripts are observed. Analysis aspects of the work support the discussion about its initial reception and its role in the clarinet literature.

Keywords: Carl Nielsen; clarinet concerto; music analysis and interpretation.

\section{1 - Introdução}

Composto em 1928, o Concerto para Clarineta, Op.57, de Carl Nielsen (1865-1931) foi dedicado ao clarinetista dinamarquês Aage Oxenvad como parte da promessa de composição de um concerto para cada membro do quinteto de sopros do qual Oxenvad fazia parte. Gradativamente, o Concerto tornou-se uma obra importante na literatura da clarineta no século $X X$, sendo executado em concursos e concertos, além de amplamente gravado por instrumentistas do mundo todo.

Com frequência, a linguagem do compositor associada à textura densa e à complexidade estrutural dessa obra suscitam questões inerentes à sua performance que permitem múltiplas abordagens interpretativas. As gravações pesquisadas demonstram que esse caráter subjetivo da performance permite certo grau de flexibilidade da interpretação como um ato de reconstrução que justapõe o mundo do compositor e do intérprete (NATTIEZ, 1993, p.144). Ainda assim, a tímida menção na literatura à gravação do Concerto de Nielsen pelo jazzista Benny Goodman demonstra que a interpretação não pode ser definida somente como expressão de sentimentos, já que incorpora aspectos como a estética, a filosofia e a história (LABOISSIĖRE, 2007, p.187). A questão implícita nesse caso é que ao intérprete (e ao público) informado, a coerência dessas escolhas está ligada, entre outros aspectos, à sua relação com as evidências conhecidas sobre a obra e seu contexto, e ao uso que se faz delas. 
A presente pesquisa procura discutir algumas dessas questões através de uma revisão na literatura específica sobre o Concerto para Clarineta, 0p.57, de Carl Nielsen. Inicialmente, buscou-se explorar a contextualização à época do Concerto, com ênfase nos aspectos relevantes sobre o compositor e a produção da obra. Em seguida, assinalam-se algumas das divergências encontradas na literatura que compara a edição impressa da Samfundet conhecida e os originais manuscritos. Passando por uma abordagem analítica da obra, a pesquisa busca discutir ainda aspectos interpretativos do Concerto, com ênfase na sua recepção inicial e o que representou desde então até nossos dias.

\section{2 - Contextualização histórica}

De origem camponesa, o dinamarquês Carl Nielsen aprendeu a tocar violino, piano e trompete desde cedo. Nascido em Sortelung em 9 de janeiro de 1865, Nielsen tornou-se o principal compositor de seu país e um dos principais sinfonistas do século XX (BURROWS \& WIFFEN, 2007, p.312). Defensor do folclore e do nacionalismo musical, ele não demonstrou interesse pela escola de Schoenberg (BUTLER, 2004, p.77), podendo ser considerado um dos primeiros a transformar os complexos harmônicos verticais de Strauss e Reger na polifonia linear moderna (Jacobsen citado por NELSON, 1987, p.40). Esse aspecto, realçado pela sua predileção por obras contrapontísticas de compositores como Palestrina, Bach e Mozart, associado à aparente constituição rústica e primitiva de sua música são suas características marcantes (NELSON, 1987, p.32-30). Niels KRABBE argumenta ainda como a imagem do compositor harmonioso que a tradição evoca demonstra ser apenas a aparência externa da sua personalidade, e que a vida pessoal de Nielsen, suas dúvidas e receios, além da frustração com a recepção com muitas de suas obras o aproximam mais do homem que do mito (KRABBE, 2012).

Sua obra para clarineta não é extensa, e inclui uma curta Fantasia para clarineta e piano de 1891, e sobretudo música de câmara, como a Serenata in Vano de 1914 e o famoso Quinteto de Sopros de 1922. As poucas obras escritas para o instrumento somado aos fatores conhecidos sobre a contextualização do Concerto para Clarineta indicam que, como muitos compositores, a sua contribuição provavelmente não teria se dado sem a participação de um intérprete que o influenciasse. Essa relação compositorintérprete não só é comum na literatura da clarineta como tornou possível obras importantes para o seu repertório. Exemplo disso é a colaboração entre Mozart e Anton Stadler, Spohr e Hermstedt, Weber e Baerman, Brahms e Mühlfeld, citando ainda Boulez e Damiens (ARAÚJO, 2006, p.3). No caso do Concerto para Clarineta, Op.57 de Carl Nielsen, essa colaboração foi com um intérprete em particular, Aage Oxenvad (WESTON, 1982, p.190). 0 clarinetista atuou conjuntamente com Nielsen durante a sua composição, e há várias referências que sugerem certa similaridade entre o caráter do Concerto e a personalidade de Oxenvad (NELSON, 2012a; GIACONA, 2009; MONROE,
2008; PETERSEN, 2002; BRYANT, 2001, p.207; BINGHAM, 1990; NELSON, 1987).

Amigo pessoal de Carl Nielsen e de origem camponesa tal qual o compositor, Oxenvad foi um amante da vida no campo e optou por viver numa pequena casa na periferia de Copenhagen. Ele era tido como um homem de humor instável; considerado um homem de "caráter forte" e cuja personalidade era uma "mistura enigmática de ternura e agressão" (BRYANT, 2001, p.207), e ainda um "clarinetista único e temperamental" (PETERSEN, 2002, p.xxxvi). Ele próprio julgava-se como um "rabugento terrivel" quando contrariado, além de considerar que a clarineta era um instrumento somente para homens (NELSON, 2012b). Sobretudo, ele mostrava-se cético em relação à performance da clarineta que era feita fora da Dinamarca, e um de seus alunos lembra que, quando da vinda de Louis Cahuzac a Copenhagen, Oxenvad teria incentivado seus pupilos a vê-lo, "mas não muito de perto" (NELSON, 1987, p.31).

Apesar da personalidade controversa, Oxenvad demonstrava um conhecimento dinâmico e amplo do processo de performance. Muito provavelmente ele tocava com embocadura dupla ${ }^{1}$ e fazia as próprias palhetas, atividade que ensinava aos seus alunos (NELSON, 1979b). Além disso, pode ter sido o primeiro a utilizar o sistema Boehm na orquestra em que tocava e, ao que tudo indica, na Dinamarca (NELSON, 1979b). Ele estudou no Royal Conservatory de 1903 a 1905 com Carl Skjerne, ele próprio um discípulo de Richard Mühlfeld, e ocupou a vaga de primeiro clarinetista da Royal Chapel Orchestra de 1919 até 1944, embora já fosse integrante dela desde 1909 (NELSON, 1987, p.31). Não obstante, firmou-se como uma referência na clarineta em seu tempo, sendo convidado a participar do Concertgebouw em Amsterdã (convite que não aceitou), e da première dinamarquesa da versão em trio da História do Soldado de Igor Stravinsky, com o compositor ao piano (NELSON, 1987, p.31).

De fato, como clarinetista, Aage Oxenvad era tido em alta conta por Carl Nielsen. Em uma carta de recomendação em fevereiro de 1921, o compositor afirmava que não só seu talento e habilidade como instrumentista eram excepcionais, como sua força criativa e conhecimento teórico eram incomuns (PETERSEN, 2002, p.xxxvii). Oxenvad demonstrava que a consideração que tinha de Nielsen era recíproca, nutrindo um sentimento de adoração pelo compositor. Segundo suas próprias palavras, Nielsen era o grande compositor da Dinamarca (NELSON, 2012b).

Em 1922, Nielsen compôs o seu Quinteto, Op.43, para o grupo do qual Oxenvad fazia parte, motivado inicialmente por tê-los ouvido ensaiar a Sinfonia Concertante de Mozart (FELUMG, 2012). A promessa de composição de um concerto para cada integrante do grupo não se realizou de imediato, e somente foi concretizada em partes; em 1926 ele escreveria o Concerto para Flauta e em 1928, o Concerto para Clarineta, 0p.57, "uma velha promessa a 
Oxenvad" segundo o compositor em entrevista datada de janeiro do mesmo ano (PETERSEN, 2002, p.xxxviii).

As mensagens trocadas entre compositor e intérprete demonstram que eles discutiam regularmente os detalhes da obra durante a sua composição. Em meados de junho de 1928, Nielsen pedia a Oxenvad que viesse almoçar com ele e trouxesse o instrumento porque ele estava quase acabando e queria ver "algumas coisas sobre o staccato outra vez" (PETERSEN, 2002, p.xxxix), numa referência provável à longa passagem em staccato dos c.189 a c.195. Nos manuscritos enviados a Oxenvad há um comentário do compositor referente a uma longa passagem em legatto dos c.688 a c. $696^{2}$, onde ele perguntava como o clarinetista poderia gerenciar a questão da respiração. $A$ resposta tranquilizadora de 0xenvad escrita logo abaixo pede para que ele não se preocupasse que ele daria um jeito, ao que o compositor torna a responder agradecendo (NELSON, 2012b; PETERSON, 2002, p.xl). Ainda segundo Oxenvad com relação ao Concerto, Op.57, ele teria recebido os manuscritos à medida que iam ficando prontos, com observações amigáveis do compositor entre as notas (OXENVAD, 1928).

Porvolta de agosto de 1928 quando a peça estava terminada, Nielsen escreveu a Carl Johan Michaelsen dizendo-se ansioso para ouvir o que Oxenvad faria dela, e que se ele não pudesse fazê-lo, ninguém poderia (PETERSEN, 2002, xli). 0 Concerto foi estreado em 14 de setembro desse mesmo ano numa audição privada na casa de Carl Johan Michaelsen, em Højtofte, tendo como solista Oxenvad e a direção de Emil Telmányi. Os músicos da orquestra eram todos integrantes da Royal Orchestra, "trazidos de ônibus de Copenhagen" (SCHOUSBOE, 1983, p.301). A primeira performance pública foi dada no mês seguinte, no dia 11 de outubro, novamente com Oxenvad, Temányi e a Royal Orchestra; uma segunda foi feita em 10 de dezembro do mesmo ano, desta vez com o compositor como regente (PETERSEN, 2002, p.xliii). Na ocasião, ele demonstrou maior satisfação com a interpretação de Oxenvad e julgou que o público teria entendido melhor a performance e a obra. A obra foi executada por seis vezes durante a vida de Nielsen, sedo que ele conduziria o Concerto 0p.57 pela última vez em 26 de outubro de 1929.

Com a saúde debilitada desde 1926, quando sofreu o primeiro de uma série de ataques cardíacos (MONROE, 2004, p.ii), Nielsen veio a falecer em 1931, sendo o
Concerto para Clarineta sua última obra de grande porte (BRYANT, 2001, p.207; NELSON, 1979a, p.47). 0 clarinetista para quem a obra foi composta faleceu em 1944, treze anos após a morte do compositor. E embora ele tenha sido um profissional bem sucedido com uma influência no ensino e na performance da clarineta na Dinamarca, sua trajetória ficaria marcada principalmente pela sua relação com o Concerto 0p.57 de Nielsen. Por ocasião da morte de Aage Oxenvad, o oboísta Svend Christian Felumb, integrante do quinteto do qual ambos faziam parte, teria escrito que o Concerto Op.57 não era uma obra para clarineta, mas sim para Oxenvad. Ele afirmava que o compositor havia sido "profundamente inspirado pela sua maneira peculiar de expressão na clarineta", e que provavelmente "ele nunca teria escrito essa obra sem ter ouvido Oxenvad tocar" (NELSON, 2012a).

\section{3 - Comparando as edições e os manuscritos originais}

No verão de 1931, Nielsen havia assinado um contrato com a Samfundet til Udgivelse of Dansk Musik para editar e publicar o Concerto, mas não chegou a vê-lo pronto (PETERSEN, 2002, p.xliv). A morte prematura do compositor acontece em meio ao trabalho de preparação da versão final, deixando questões em aberto na leitura dos manuscritos da grade orquestral e da redução para piano, como demonstram a correspondência entre os editores (PETERSEN, 2002, p.xlvi). Assim, embora essa edição seja a referência provável para boa parte dos instrumentistas que estudam o Concerto, Op.57, quando confrontada com os manuscritos originais preservados, é possível perceber algumas divergências entre as suas notações.

Em um artigo publicado na revista The Clarinet, o clarinetista Eric Nelson chegou à essa conclusão ao analisar comparativamente os manuscritos originais e a versão impressa (NELSON, 1987). NELSON partiu de três fontes principais: a grade orquestral mais antiga (chamada por ele de MS I), a parte solo de Oxenvad, com suas anotações pessoais (MS II) e uma versão final da partitura preparada para a sua publicação (MS III). Ele constatou, por exemplo, que no c.528, diferente da edição impressa, encontra-se nas versões manuscritas uma fermata na primeira das notas Sib em sequência quase no fim da linha (Ex1). A fermata é seguida por

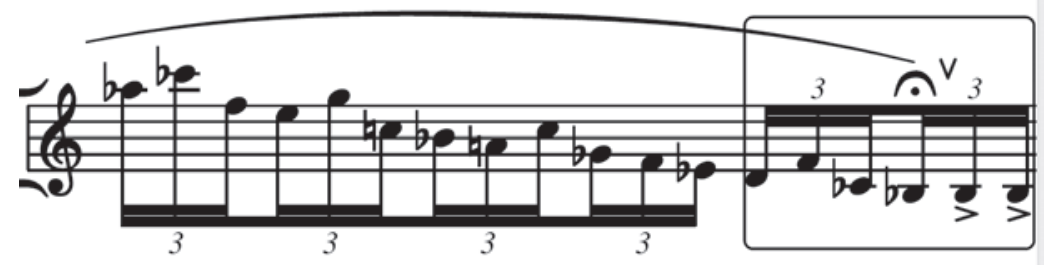

Ex.1 - Fermata e cesura na cadência do c.528 tal como consta nos originais manuscritos do Concerto para Clarineta, Op.57 de Carl Nielsen. 
uma cesura, para então dar a continuidade em agitato. Nenhuma dessas indicações (incluindo a fermata) consta na edição da Samfundet.

Outras fontes parecem confirmar a inclusão da fermata e da cesura nesse ponto; a nova edição do Concerto de Nielsen realizada em 2002 pela Wilhelm Hansen ${ }^{3}$ traz essa alteração, exatamente como demonstrada no Ex1. De acordo com PETERSEN (2002, p.xlvi), ela justifica-se por ser feita de próprio punho pelo compositor na cópia do manuscrito original do acompanhamento pelo piano, considerado fidedigno por ser revisado por Nielsen.

Logo em seguida, em outra passagem controversa no c.531, a comparação entre manuscritos originais e versão impressa pode causar confusão sobre quais seriam as notas realmente desejadas pelo compositor. De acordo com NELSON (1987, p.30), na quinta sequência de fusas desse compasso, as notas grafadas como Láb e Fáb na partitura editada seria um erro evidente de impressão. Ambas as notas seriam na verdade Sol\# e Mi, respectivamente, alterando a próxima sequência para Lá natural, conforme demonstrado nos Ex2.a e Ex2.b.

Entretanto, os trabalhos para a edição da Wilhelm Hansen disponíveis no prefácio da obra (PETERSEN, 2002, p.xvii) indicam que, apesar dessas alterações realmente constarem tal como grafado no Ex2.b tanto na parte solo manuscrita de Oxenvad quanto na de Emil Telmányi ${ }^{4}$, elas não são transferidas para a cópia revisada pelo compositor. Telmányi, entretanto, não era uma referência adequada como se verá a seguir. Quanto ao c.531, Elly PETERSEN argumenta pela manutenção das notas Láb e Fáb (Ex2.a), uma vez que Nielsen era tido como cuidadoso ao indicar alterações (PETERSEN, 2002, p.xvii).

Mesmo uma análise fraseológica não chega a sugerir um argumento claro para essa mudança; a sequência ascendente inicia ainda no compasso anterior com [DóRé-Sol-Láb], [Fá-Sol-Dó-Ré], [Sib-Dó-Fá-Láb] e [FábLáb-Dó-Mi]. Em cada sequência dessas, se considerarmos que as duas primeiras notas iniciam um movimento melódico ascendente, mas que são as duas últimas que estabelecem uma relação de tensão crescente por aumento intervalar (meio tom na primeira, Sol-Láb, um tom na segunda, Dó-Ré, e assim por diante), ainda assim não seria possível determinar qual das versões (Ex2.a ou Ex2.b) seria a correta. Segundo o editor da Wilhelm Hansen, o mais provável é que os copistas de ambas as cópias tenham se esquecido da alteração nas partes manuscritas (PETERSEN, 2002, p.xlvii).

A pouca quantidade de rascunhos que Nielsen deixou indica que ele trabalhava as ideias relativas às obras que compunha no momento da composição, não sendo costume manter ideias anotadas para futuros projetos. De fato, esse parece ser um padrão do seu processo composicional (PETERSEN, 2005, p.197). Dessa maneira, parece razoável supor que as obras podiam sofrer consideráveis alterações por motivos mais variados possíveis; seja por um pedido do intérprete, uma primeira apresentação pouco convincente, e assim por diante. É sabido, contudo, que embora seus esboços contenham poucas informações sobre articulações e dinâmicas, eles são bastante consistentes no que diz respeito à sua publicação posterior em relação à notação grafada e ao ritmo (PETERSEN, 2005, p.197). Isso pode indicar que a opção de manter a notação tal qual o Ex2.a é a mais adequada por basear-se nesses esboços feitos para a impressão da obra. Além disso, esse fato pode indicar que algumas questões eram deixadas em aberto para discussões com os intérpretes, mas que outras eram imprescindíveis em sua opinião, ou ao menos se não constituíssem um problema à performance.

Esse parece ser o caso desse exemplo em particular, em que a comparação dos manuscritos possibilita entender como Nielsen e Oxenvad pensaram e solucionaram certas passagens. No c.192, página 4, linha 9 da edição da Sanfundet, há uma pausa durante a sequência de staccatos. Nas versões manuscritas pesquisadas, a indicação inicial parece ser a de uma linha contínua de staccatos, conforme indicado no manuscrito da parte solo de Oxenvad, Ex3.a.

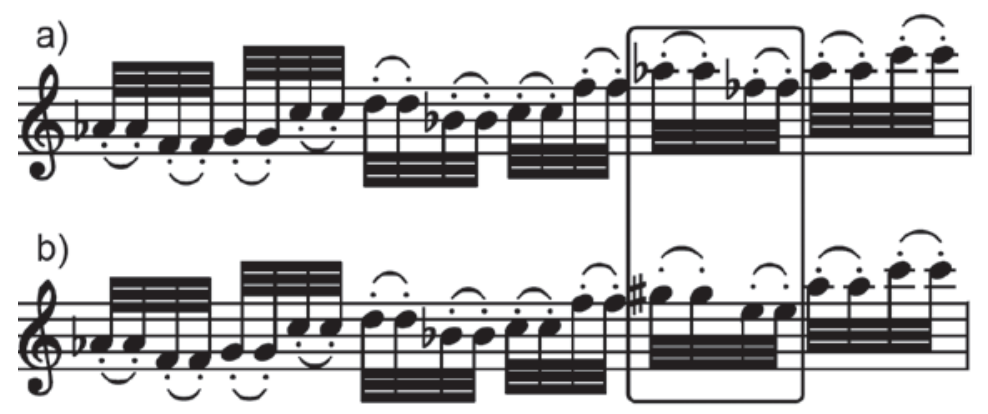

Ex.2 - Enarmonia verificada na comparação entre versão editada da Samfundet, na qual a última sequência é Láb (a) e originais manuscritos (b), onde seria Lá natural, no c.531 do Concerto para Clarineta, Op.57 de Carl Nielsen. 
a)

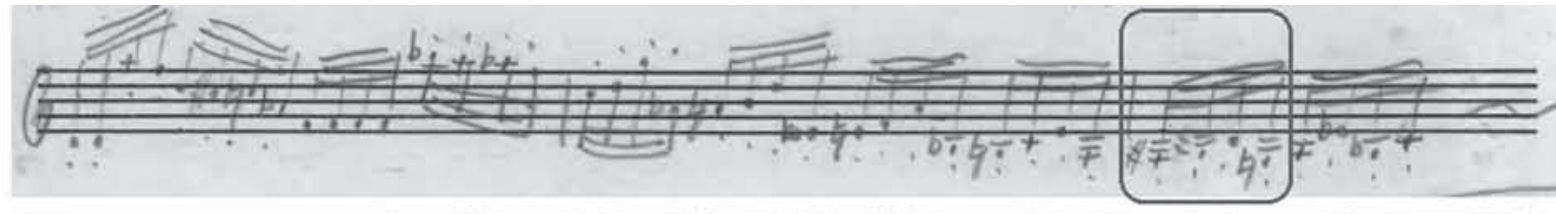

b)

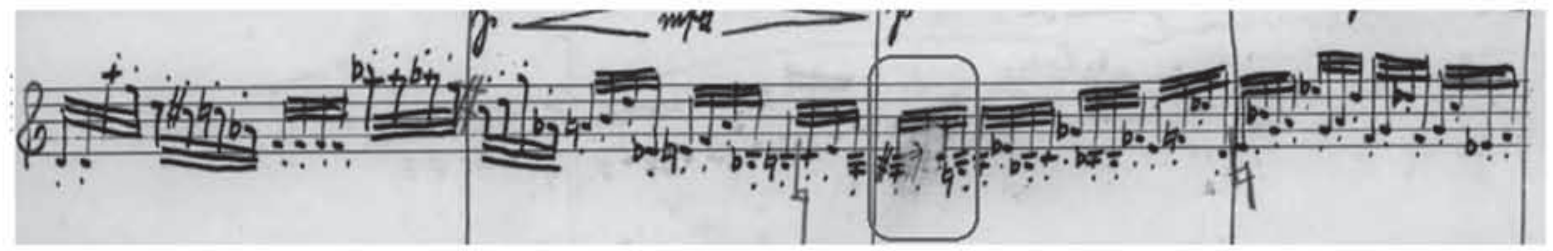

C)

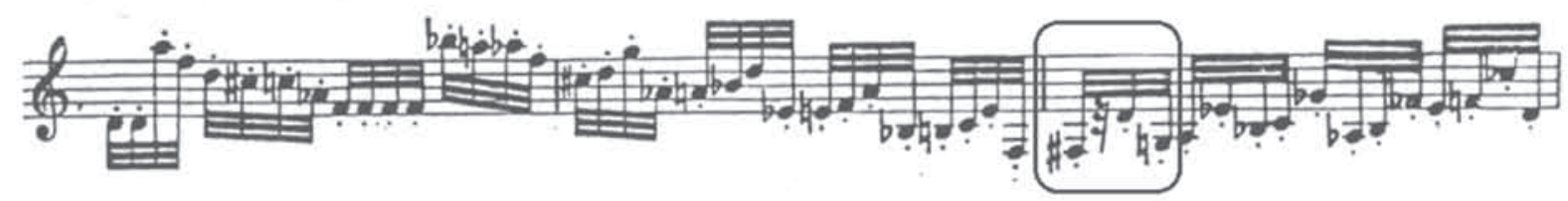

Ex.3 - Diferentes grafias no c.192 nos trechos em staccato constantes nos manuscritos originais de Oxenvad (a), na grade orquestral (b) e na edição Sanfundet (c), do Concerto para Clarineta, Op.57 de Carl Nielsen.

a)

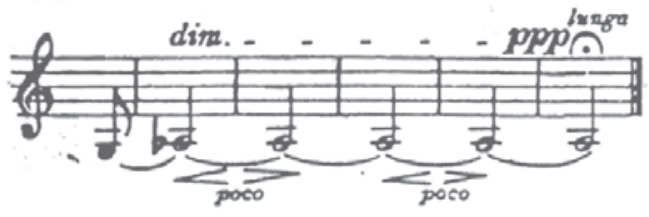

b)

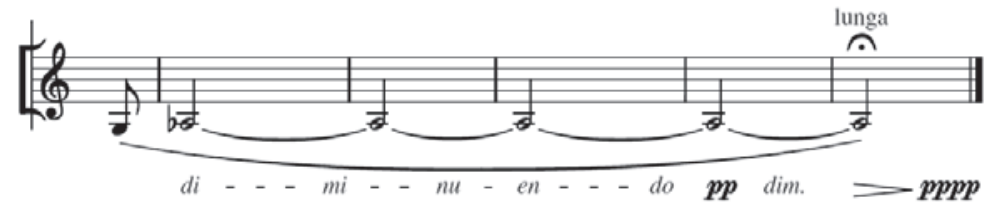

Ex.4 - Compassos finais das edições Samfundet (a) e Wilhelm Hansen (b) do Concerto para Clarineta, Op.57 de Carl Nielsen, com as diferentes indicações de dinâmica em cada uma.

Entretanto, ao que tudo indica, Oxenvad teria sugerido ao compositor uma pausa pequena para respiração nesse trecho (PETERSEN, 2002, p.xlvi). Essa pausa aparece como correção na grade orquestral manuscrita (Ex3.b), bem como na versão editada da Samfundet (Ex3.c) e na nova edição da Wilhelm Hansen (PETERSEN \& PETERSEN, 2002, p. 206). A longa passagem em staccato constitui-se ainda hoje num dos principais problemas técnicos a ser resolvidos pelo intérprete da obra. A grafia anterior de uma linha ininterrupta por seis compassos sugere de fato que a dificuldade do trecho seria ainda maior, fator que Oxenvad deve ter sublinhado ao compositor.

Na edição da Wilhelm Hansen, é possível constatar ainda diversas alterações nas indicações tanto da parte solo da clarineta quanto da orquestra em relação à edição da Samfundet. De uma forma geral, elas divergem no tocante ao início e término de algumas ligaduras e à forma de ataque de algumas notas. Sobretudo, há uma mudança significativa nos últimos compassos da parte solista, no trecho em decrescendo a partir do c.724 (Ex4).
Observa-se que na parte solista editada pela Samfundet, há duas indicações de crescendo e decrescendo $(<>)$ dentro do âmbito do diminuendo geral (Ex4.a). Essas indicações, no entanto, não aparecem na nova edição da Wilhelm Hansen (Ex4.b), que toma como base para resolver eventuais duplicidades os manuscritos revisados pelo compositor (PETERSEN, 2002, p.xvi). As fontes utilizadas pelos editores da Wilhem Hansen constituemse, sobretudo, de manuscritos originais autografados pelo compositor, que incluem um esquema contendo os principais temas da clarineta com uma redução orquestral em dois pentagramas, projetos nos quais as cópias para impressão se baseariam, a própria edição da Samfundet til Udgivelse af Dansk Musik, além de outras cópias que estavam em posse de Oxenvad e foram doadas por ele à Royal Library (PETERSEN, 2002, p.254-256).

Conforme informação disponivel no prefácio da obra, os critérios adotados na edição foram de remover as adições feitas por amigos e colegas, salvo exceções comentadas no prefácio (PETERSEN, 2002, p.viii). Há indicações que Emil 
Telmányi teria sugerido modificações no Concerto Op.57 que foram aceitas por Nielsen, como a troca do acorde que as trompas executavam dos c.546 a c.551 para que fizessem a mesma melodia dos fagotes (PETERSEN, 2005, p.198). Entretanto, ele também teria, aparentemente por sua conta, suprimido a parte do baixo da orquestração logo após a sua première (PETERSEN, 2002, p.314), no que KRABBE chamou de um dos muitos relatos na tradição de Nielsen de maestros "atendendo o chamado de melhorar" sua partitura (KRABBE, 2003, p.103). Como os originais manuscritos do Concerto que estavam em sua posse estão repletos de alterações que fez de próprio punho (PETERSEN, 2002, p.314-315), e uma vez que não se sabe o que seria aprovado por Nielsen e o que não, a decisão de retirar seus acréscimos parece coerente nesse caso.

No entanto, embora esses e outros critérios sejam discutidos previamente no prefácio da obra, que inclui algumas páginas dos manuscritos citados, uma das decisões controversas é não indicar graficamente na partitura quais foram as adições editoriais. As indicações presentes a esse respeito são confusas, com fontes pequenas e uma quantidade de detalhes que, sem a visualização do compasso em questão, dificultam o acesso a essas informações. Segundo os editores, articulações, dinâmicas, hastes e ligaduras foram "normalizadas com base em analogias entre passagens semelhantes" (PETERSEN, 2002, p.viii). Essas alterações não indicadas, entretanto, podem induzir o leitor a pensar que o documento corresponde sob todos os aspectos ao revisado por Nielsen. Aos intérpretes interessados na escrita original do compositor e cujos manuscritos originais são inacessíveis, esse cuidado é fundamental na tomada de decisões e escolhas interpretativas.

\section{4 - Análise e interpretação}

A orquestração requerida para o Concerto para Clarineta, Op.57 de Carl Nielsen parece modesta se comparada às grandes massas orquestrais de seus contemporâneos. Escrito para clarineta em Lá como solista, a instrumentação inclui além das cordas (violinos, violas, violoncelos e contrabaixo), somente dois fagotes, duas trompas e a caixa clara. Em sua correspondência, Nielsen deixa claro que tanto a clarineta solista quanto as partes orquestrais foram tratados da forma mais individual possível, e que seus objetivos eram a clareza e o rigor (PETERSEN, 2002, p.xli), numa narrativa extensa e ininterrupta.

Contudo, mesmo sendo executado continuamente e sem pausas, o Concerto é normalmente considerado em quatro movimentos distintos na literatura pesquisada (GIACONA, 2009; MONROE, 2008; ROSENBERG, 1966; MAEGARD, 1956; MEYER, 1947), seguindo de uma maneira geral a menção que o próprio Nielsen faz a essa divisão em suas cartas (PETERSEN, 2002, p.xxxviii). Essas seções são normalmente nomeadas como $1^{\circ}$ Movimento, indo do começo do Concerto até o c.218 (Ex5.1) e englobando
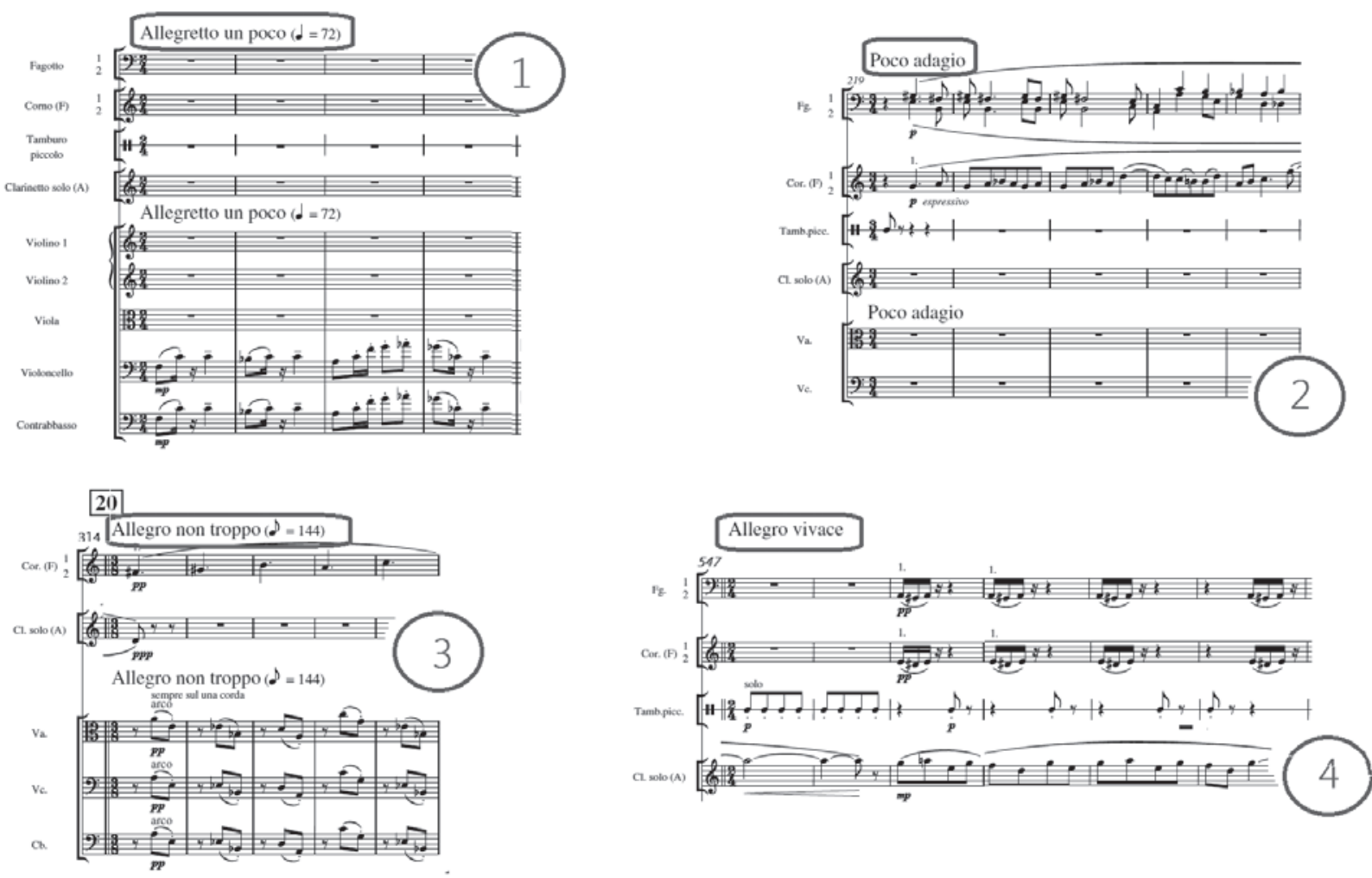

Ex.5 - Divisão formal do Concerto, Op.57 de Carl Nielsen, numerados como 1 (c.1-218), 2 (c.219-313), 3 (c.314-546) e 4 (c.547 ao fim). 
os andamentos Allegretto un poco, Allegro non tropo, Più Allegro e Tempo I; $2^{\circ}$ Movimento, Poco Adagio, do c.219 até c.313 (Ex5.2); $3^{\circ}$ Movimento, do c.314 a c.546 (Ex5.3), que inclui o Allegro non tropo, Poco più mosso e Adagio; e $4^{\circ}$ Movimento, do c.547 até o fim (Ex5.4), cujos andamentos são Allegro Vivace, Poco adagio e Allegro.

Ainda assim, essa divisão não é unânime ou ainda desnecessária na visão de intérpretes como o clarinetista Kjell-Inge Stevensson. Para ele, a obra é mais uma questão de humores e alternâncias, sem a necessidade de uma divisão em seções distintas (Stevensson citado por NELSON, 1979a, p.76).

De fato, a relação intrínseca entre esses movimentos devido à recorrência do material temático e suas transformações durante a obra contribuem para a unidade da peça, ainda que essas transformações por vezes criem ambientes sonoros absolutamente contrastantes. 0 próprio Nielsen comentou seu entusiasmo nessa obra pela quantidade de coisas expressas a partir de um tema quase infantil, ainda que não soubesse dizer se isso seria uma coisa boa ou não (PETERSEN, 2002, p.xxxvi). Alguns acham que não.

Em seu livro The Clarinet and the Clarinet Playing, David PINO (PINO, 1980) salienta essa prolixidade como um dos principais problemas da obra. De acordo com o autor, há elementos temáticos suficientes para muitos concertos, mas eles não são desenvolvidos de uma forma significativamente satisfatória (PINO, 1980, p.264). Além disso, o Concerto se moveria de ideia em ideia sem cuidado ou conexão, e com quase total ausência de recapitulação ou desenvolvimento (PINO, 1980, p.264). No entanto, aparentemente o autor tenta incluir - Concerto, Op.57 numa visão formal pouco adequada, e cujas condições a estrutura da peça não satisfaz, o que pode ter sido determinante no enfoque do seu comentário. Uma observação atenta demonstra que as transformações rítmicas e melódicas do tema principal são a base para o agrupamento das ideias do Concerto em torno de seções ou trechos.
Esse tema principal é ouvido já nos primeiros compassos (conforme demonstrado nos Ex6.1 e Ex6.2), uma quinta justa que soa como uma dança tradicional camponesa, no formato longa-curta-longa (Ex6.2), ou "bate-chutabate" [o pé] ${ }^{5}$. Esse tema inicial do Concerto incorpora o elemento de unificação da narrativa, com um caráter mais movido e agitado na sua forma ascendente, mais reflexivo quando aparece invertido, conforme Ex6.3 (MONROE, 2008, pp.20-21). Além disso, o mesmo motivo é usado por vezes no contraponto da orquestra em relação ao solista (Ex6.5).

0 segundo tema aparece no c.79, com uma figuração geralmente descendente e claramente mais lírico que 0 anterior. Esse contraste com o primeiro tema é reforçado com a indicação de que a passagem seja tocada de forma mais tranquila e em dinâmica piano espressivo. Nesse ponto, o acompanhamento orquestral é feito inicialmente pelos fagotes, que se movem mais lentamente (em semínimas) com intervalos de terças e quintas entre eles. Do c.109 em diante, há uma tensão crescente tanto na orquestração quanto na parte solista, construida com uma troca de passagens curtas marcadas pela rapidez e uma estridência cada vez maior entre ambos. Essa tensão conduz a obra até a primeira grande cadência da clarineta no c.133, que apresenta uma série de variações dos principais motivos melódicos e rítmicos usados até então no Concerto, Op.57.

Pouco depois do fim dessa cadência, há uma reexposição clara no c.150 (ou n.8 na partitura) em que o primeiro tema é ouvido integralmente, embora não haja qualquer menção ao segundo. Em seu lugar, Nielsen inicia o que GRIMLEY chama de "um cuidadoso processo controlado de colapso composicional" (GRIMLEY, 2003, p.34), em que a clarineta repete de forma incisiva o primeiro tema e a orquestra executa uma progressão em semicolcheias por ciclos de quintas que impõe um caráter cada vez mais movido e intenso, com eventuais trocas de material rítmico e melódico entre solista e orquestra, e que segue praticamente até o início do segundo movimento, Poco Adagio, no c.210.

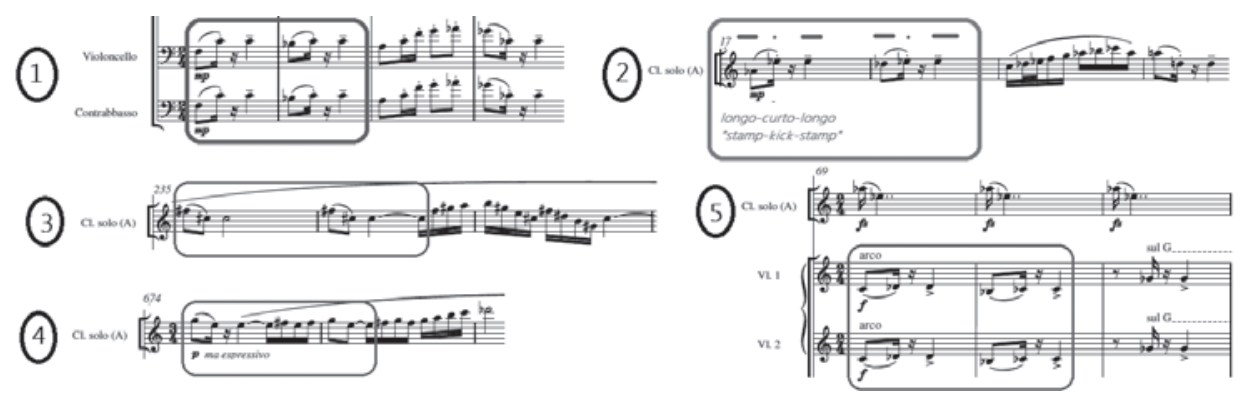

Ex.6 - Excertos demonstrando a recorrência temática do Concerto para Clarineta, Op.57 de Carl Nielsen. 
Allegretto un poco. Allegro non troppo. Piú allegro. Tempo I. (mvt. 1)

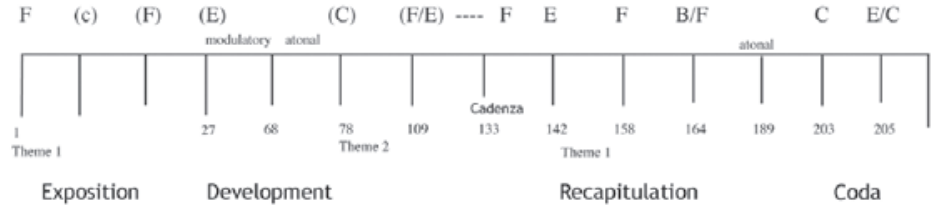

Ex.7 - Análise do 10 Movimento do Concerto, Op.57 de Carl Nielsen por Ann Marie Bingham.

Esse movimento foi esquematizado pela clarinetista Ann Marie BINGHAM (BINGHAM, 1990), tal qual como demonstra o Ex7. 0 esquema faz parte de uma proposta analítica da autora sobre cada um dos movimentos (Bingham citado por GIACONA, 2009, p.12), partindo inicialmente da divisão formal da obra proposta por ROSENBERG (1966).

Além de algumas das características salientadas anteriormente, o esquema de BINGHAM chama a atenção por ressaltar ainda outros aspectos considerados importantes pela autora, como por exemplo, a delimitação da estrutura da peça com base no aparecimento de temas e seus desenvolvimentos, quando considerou o caso. É possível notar a ênfase dada pela autora na forma de exposição, desenvolvimento e recapitulação, seguida de uma coda que encerra o movimento, tal qual uma forma sonata.

Sobretudo, são ressaltados os centros tonais da obra, com uma predominância das tonalidades de Fá e Mi maior, cadenciadas pela presença dos acordes de Dó e, menos frequentemente, $\mathrm{Si}$ maior, respectivamente suas dominantes. Passagens modulatórias (Ex7, c.27) e duas atonais (Ex7, c.68 e c.189) são destacadas no esquema. De acordo com a autora, esses dois acordes, Dó e Si maior, dominariam a exposição do tema no segundo movimento, formado por três seções internas distintas, no que chamou de forma A-B-A'. A sua análise nos outros dois movimentos dá continuidade ao conflito tonal entre Fá e Mi. No terceiro (em 3/8 a partir do c.305), definido como uma seção intermediária entre o formato ternário proposto no segundo movimento e a forma rondó encontrada no quarto (Bingham citada por GIACONA, 2009, p.14), elas aparecem alternadamente na sucessão de temas, cadenciando em Mi maior após a cadenza final da clarineta no movimento; no quarto e último movimento, Mi e Si maior aparecem eventualmente, mas o esquema sublinha o término do movimento em Fá maior.

Ann Marie Bingham não é única a destacar o papel desse conflito tonal no Concerto, Op.57 de Nielsen. Abordagens semelhantes são encontradas na literatura específica (GIACONA, 2009; MONROE, 2008; SIMPSON, 1986; NELSON,1979a), demonstrando um viés analítico que tende a caracterizar a obra, embora não exclusivamente, por essa ambiguidade tonal.
Assim, aspectos como o conflito tonal entre Fá e Mi maior foram sublinhados pela análise de NELSON (1979a, p.71), mas também a manipulação melódica na obra, as passagens politonais (c.210 a c.213, por exemplo) e em escalas de tons inteiros (c.64 na parte da clarineta), bem como passagens atonais, como na cadência solo da clarineta em staccato do c.189 ao 196, "ainda que com uma leitura mais pessoal do termo por parte do compositor" (NELSON, 1979a, p.71). Ainda mais longe projeta MONROE (2008), que propõe uma análise através de significados extras musicais do Concerto, 0p.57, e para quem as transformações do tema inicial através da obra são um reflexo de raiva, terror e loucura (MONROE, 2008, p.23). 0 autor traça um paralelo entre a obra de Nielsen com a teoria da doutora Elizabeth Kübler-Ross sobre a aceitação da morte iminente através dos estágios de negação, raiva, barganha, depressão e aceitação. Para ele, é possível identificar na obra reflexos desses estágios, que são por sua vez fruto da saúde cada vez mais debilitada de Nielsen à época da composição do Concerto. Mas as evidências que fornecem são insuficientes para apoiar suas conclusões. Por exemplo, ele assume sem maiores explicações que as variações rítmicas do tema são "um sinal ao ouvinte que algo não está bem" (MONROE, 2008, p.16). E em alguns aspectos, seu trabalho soa como um ajuste dos fatos à teoria.

Com efeito, é sabido que atribuir ideias extramusicais ao discurso musical é uma associação delicada, uma vez que o significado é uma construção que envolve o que o ouvinte conhece a respeito, varia com o contexto e muitas vezes depende de interpretação subjetiva (BURKHOLDER, 2006, p.102). Onde o autor vê raiva ou desespero, qualquer outro ouvinte poderia ver somente um caráter marcial, ou mesmo cômico. Se mesmo noções básicas de consonância e dissonância podem gerar significações múltiplas, quando não contraditórias (Butler citado por GREEN \& BUTLER, 2006, p.265), buscar através da análise da estrutura da obra motivações que a ultrapassem pode ser extremamente difícil, quando não impossível.

Sobretudo, o problema de análises com uma ênfase nessa dicotomia tonal do Concerto, 0p.57 de Nielsen é que a tentativa de enquadramento da estrutura da obra em modelos formais convencionais tende a sublinhar excessivamente aspectos particulares e por vezes de 
menor importância. Em sua análise da $4^{a}$ Sinfonia, Op.29 do compositor, WHITE salienta que a ocorrência tonal em Nielsen possui no geral uma intenção mais ampla, independente da evidência aural local que possua (WHITE, 1991, p.xxii). Assim, no Concerto para Clarineta, o significado estrutural atribuído ao conflito tonal entre Fá e Mi maior é comprometido pela forma redundante que os centros tonais diatônicos são considerados na sintaxe harmônica do compositor, tornando difícil discernir detalhes de expressão musical locais com eventos estruturais de importância em maior escala (GRIMLEY, 2003, p. 31).

Do ponto de vista da performance, o reflexo mais nítido é a negligência de uma série de eventos não descritos em detrimento de uma polarização tonal do Concerto. A qualquer intérprete que já estudou a obra, o esquema tonal citado anteriormente por BINGHAM soa claramente insuficiente para dar conta do fraseado cromaticamente alterado ou da complexa relação construida entre solista e orquestra.
É possível verificar, por exemplo, que na primeira grande cadência da clarineta no c.133, que como já referido inclui variações melódicas e rítmicas dos temas recorrentes apresentados no Concerto, o compositor mantém a mesma figuração rítmica durante passagens inteiras em que os padrões intervalares são sucessivamente alterados, criando contrastes e direcionando a frase. Por exemplo, na linha descendente do trecho indicado no Ex8.1, o padrão de três notas é repetido e intensificado cada vez mais até o reaparecimento do tema inicial do Concerto de duas formas. Uma é pela aproximação das duas primeiras notas de cada grupo, que nas cinco primeiras sequências constituem intervalos de quarta e quinta, e posteriormente será de terça. A outra delas é pelo afastamento intervalar da última nota de cada conjunto da primeira (e da segunda, por extensão). Esse afastamento, combinado com o direcionamento para o registro grave do instrumento constrói uma tensão que atinge seu ponto máximo quando o tema inicial é ouvido a 'plenos pulmões' com a indicação de marcato e ambas as notas acentuadas (Ex8.1).
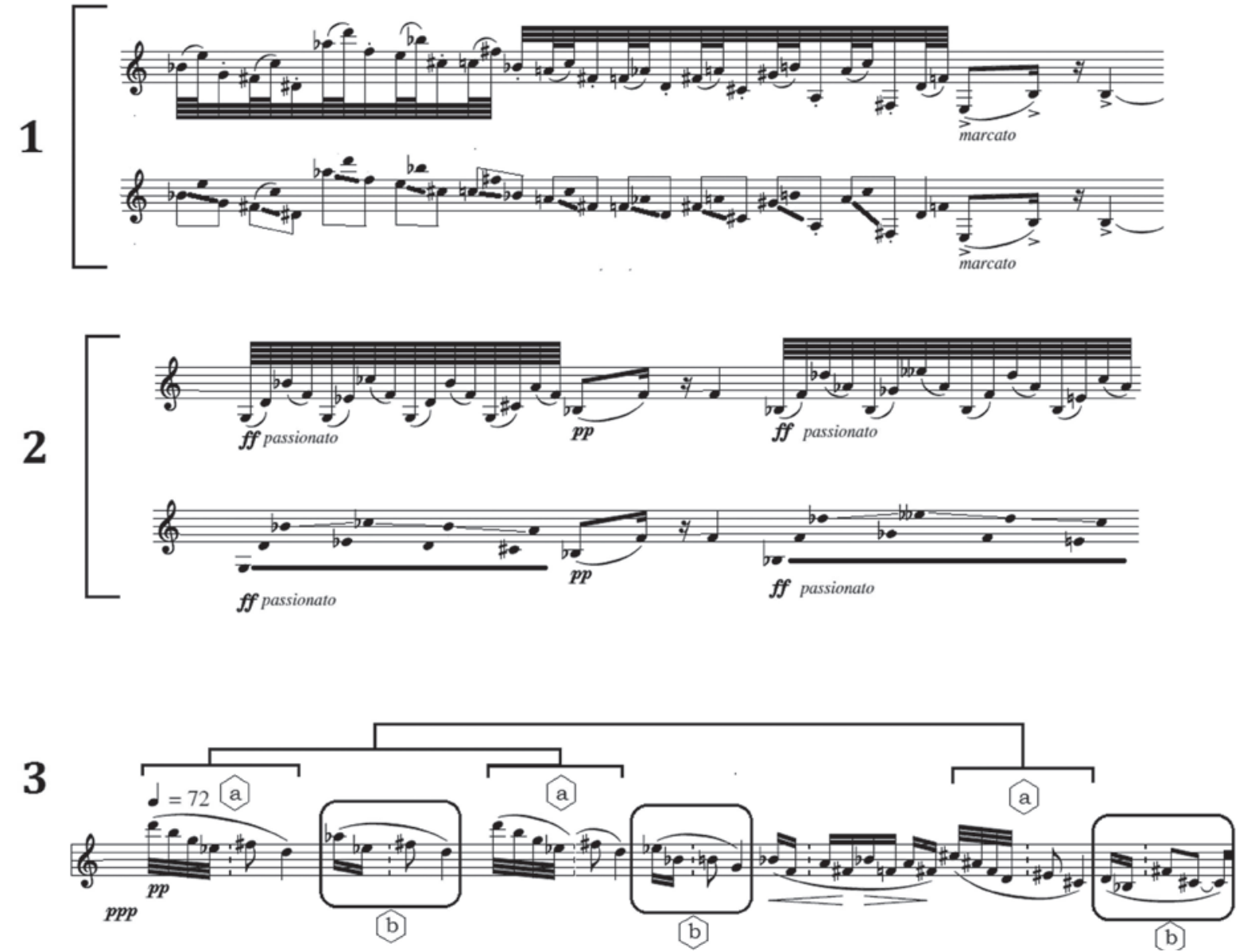

Ex.8 - Excertos da cadência da clarineta no c.133 do Concerto, Op.57 de Carl Nielsen, demonstrando a variação do padrão intervalar na construção das frases. 
Outro dos recursos utilizados é a manutenção de uma nota pedal que é constantemente reiterada pela clarineta, enquanto as notas superiores, que guardam uma relação de sexta entre si (conforme demonstrado no Ex8.2), tensionam variando a distância entre elas e esse pedal. Essa variação intervalar é utilizada também na construção de motivos rítmicos um pouco maiores, como os constituídos de dois segmentos (Ex8.a e b, respectivamente) que se completam e que aparecem por três vezes em sequência (Ex8.3). Observa-se aqui que o segmento indicado pela terceira chave (indicada como a) é uma transposição exata um semitom abaixo dos dois primeiros. Além disso, enquanto o segundo segmento (indicado por b) aparece com distâncias intervalares diferenciadas no primeiro, segundo e terceiro quadro assinalado.

Esses procedimentos utilizados por Nielsen constroem de forma cuidadosa o aspecto caótico de algumas das passagens de maior tensão entre a clarineta solista e a orquestra. De acordo com a análise de GRIMLEY (2003), um dos recursos contrapontísticos do compositor constituiu-se de uma progressão linear através de um fragmento melódico de doze notas. Baseando-se inicialmente numa progressão harmônica em quintas (Sib-Fá-Dó-Sol, respectivamente) do c.158 a c. $165^{6}$, Nielsen inicia uma sequência com um contraponto rigoroso utilizando o mesmo motivo melódico (no Ex.9 são sublinhadas as suas duas primeiras aparições no contexto) e que passa a coincidir em intervalos de oitava (sempre na terceira nota do motivo descendente) e décima (na última nota), num padrão que o autor chamou de 8-10 (GRIMLEY, 2003, p.34), tal como demonstrado no Ex.9.

Entretanto, a manutenção desse padrão torna impossiveis as consonâncias de oitavas e décimas e elas passam a ser aumentadas, como sublinhado no fim da primeira linha do Ex9. 0 efeito cumulativo dessa alteração leva o compositor a abandonar as consonâncias e utilizar intervalos de nonas menores e sétimas maiores, ou padrão 9-7, como chamado por GRIMLEY (2003, p.34). Além disso, a célula melódica é diminuída de doze para oito notas (Ex10.a) e depois seis (Ex10.b), levando a uma antecipação cada vez maior no início de cada uma delas. Toda essa seção inicia com a indicação de poco a poco accelerando, e os cromatismos e a tensão resultantes direcionam para o c. 173, marcado para ser ainda mais movido com a indicação de più allegro. Nesse ponto, a mesma célula melódica utilizada anteriormente passa a ser executada pela clarineta solista enquanto o tema inicial do Concerto é lembrado esporadicamente pelos outros instrumentos. A orquestra retoma o cromatismo anterior acelerando ainda mais enquanto a clarineta sustenta uma nota no agudo em
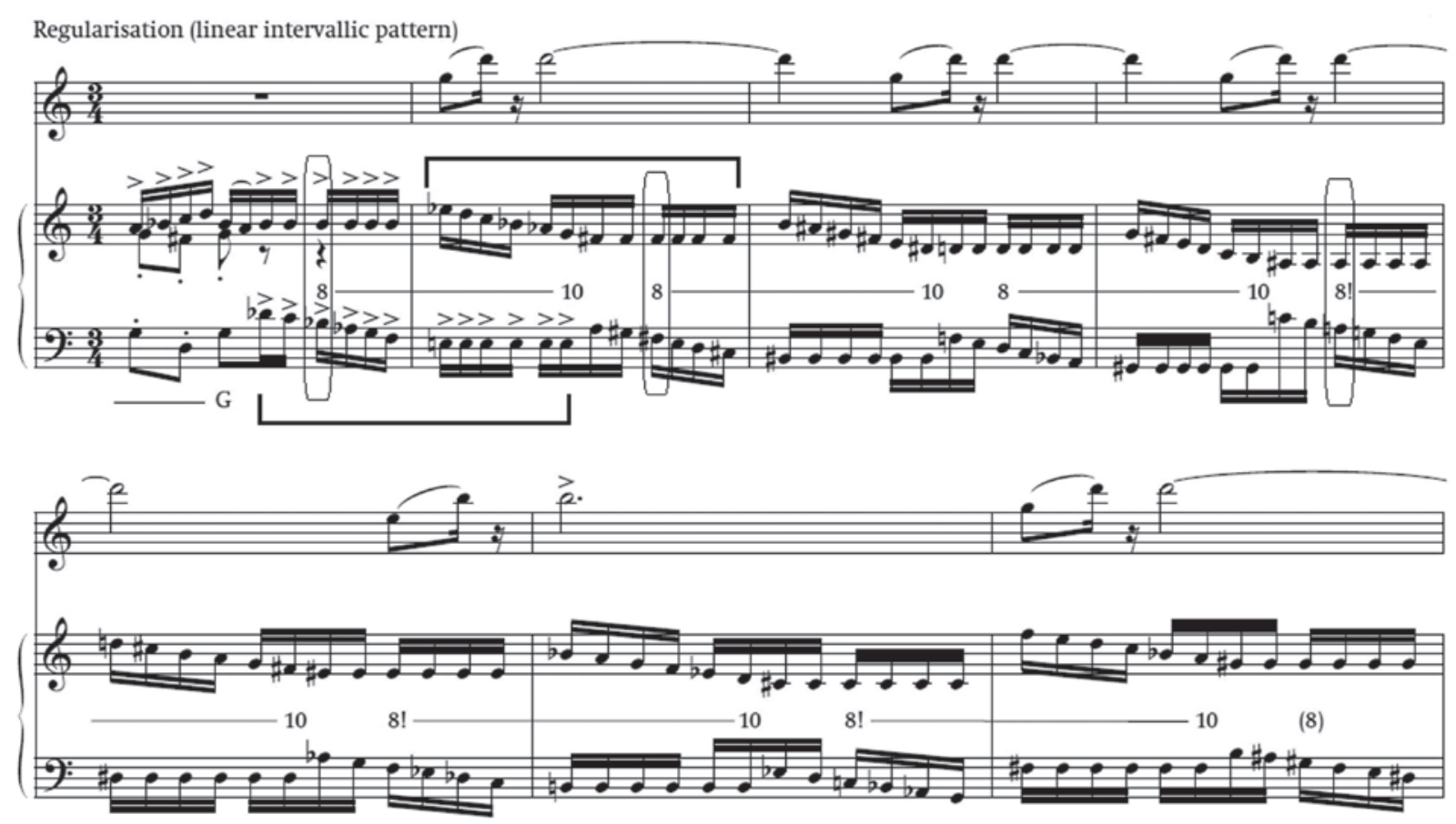

Ex.9 - Extrato da análise de GRIMLEY (2003, p.35) dos c.163-169 do Concerto para Clarineta, Op.57 de Carl Nielsen, demonstrando o padrão contrapontístico utilizado pelo compositor no trecho. 


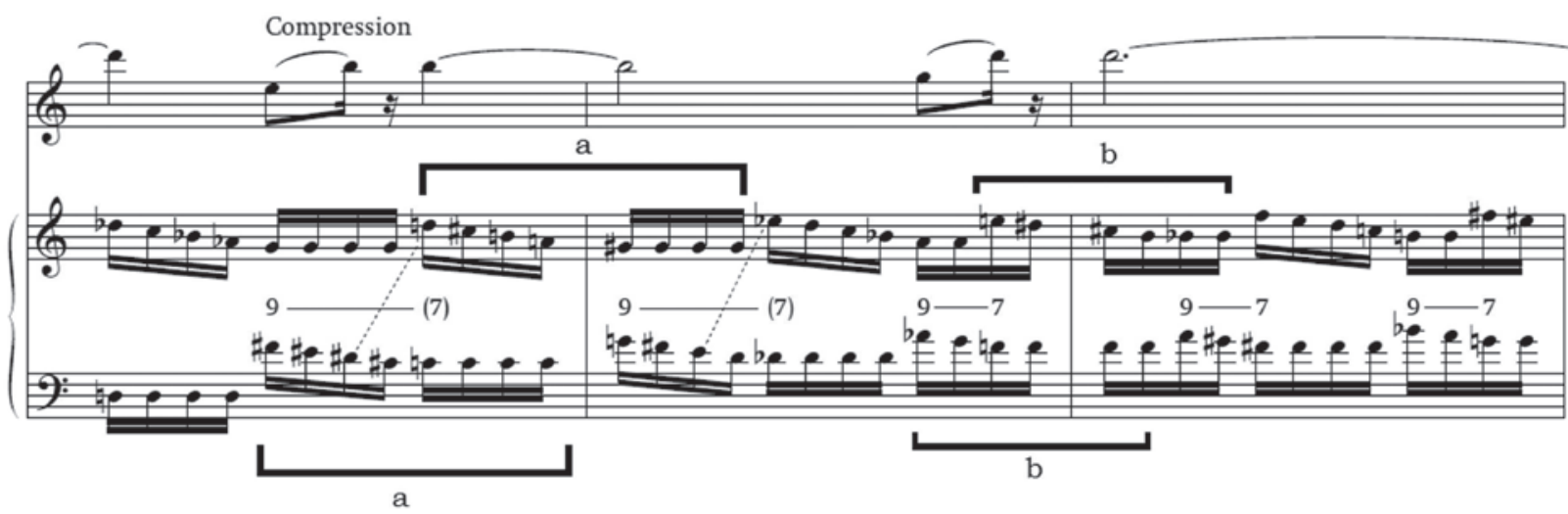

Ex.10 - Extrato da análise de Daniel GRIMLY (GRIMLY, 2005, p.35) dos c.170-172 do Concerto para Clarineta, Op.57 de Carl Nielsen, demonstrando a compressão melódica e o padrão intervalar dissonante.
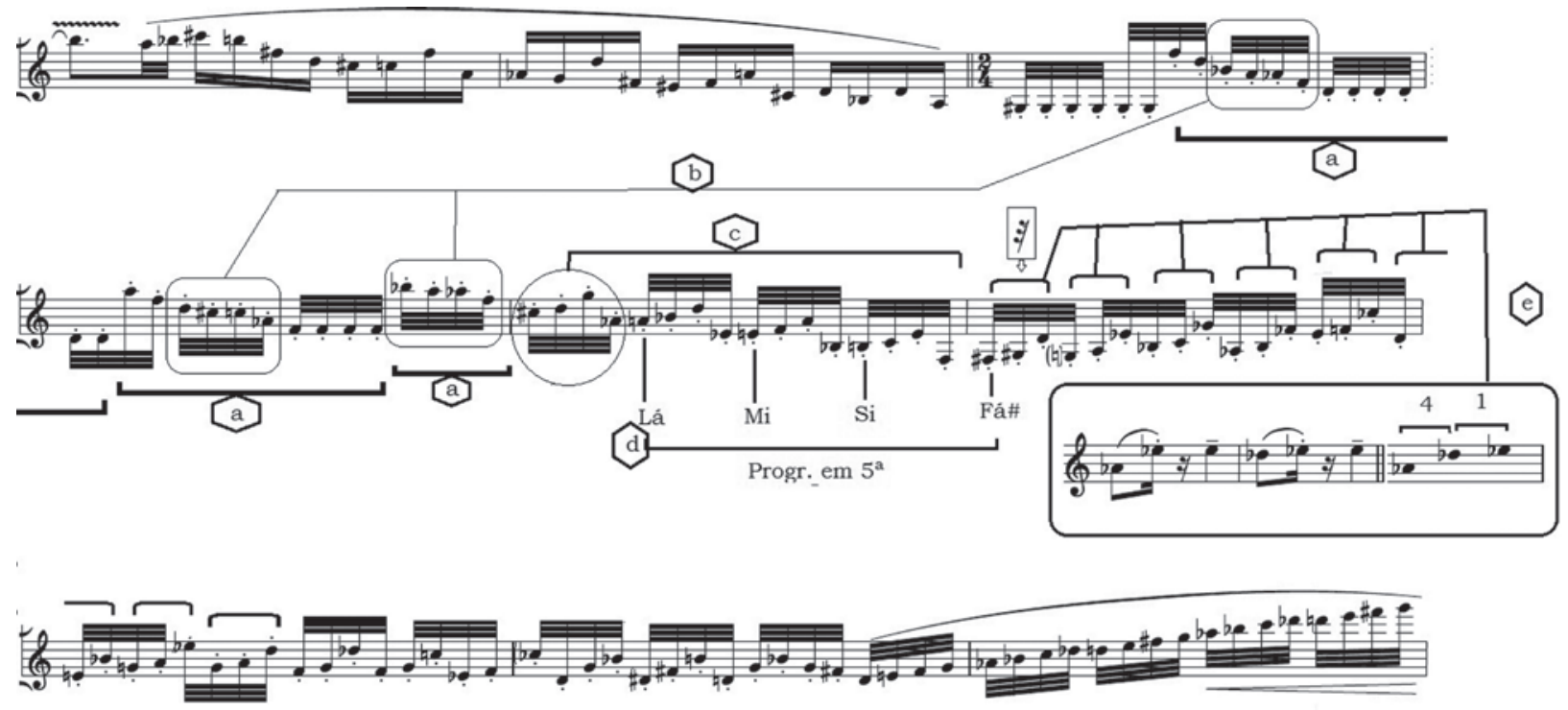

Ex.11 - Cadência da clarineta em staccato dos c.189-195 do Concerto, Op.57 de Carl Nielsen, demonstrando a recorrência temática.

trinado. A conjunção desses elementos leva diretamente à cadência em staccato que a clarineta executa dos c.189 a c.195, como demonstrado no Ex11. Nela é possível verificar procedimentos semelhantes, como a compressão melódica (Ex11.a), a recorrência de padrões transpostos (Ex11.b e c) e ainda a progressão por quintas (Ex11.d).

A cadência, que apresenta material melódico extraído da relação intervalar do tema principal (como demonstrado em Ex11.e), termina com uma escala ascendente (última linha do Ex11) em com a indicação de crescendo molto, cabendo à orquestra e às intervenções da caixa clara a retomada de um andamento menos movido, necessária para o início do segundo movimento, Poco Adagio, introduzido pelas trompas.
Nesse sentido, é importante salientar o papel que a caixa clara exerce no Concerto, Op.57. Geralmente utilizada como forma de pontuar as passagens solistas da clarineta e da orquestra, sua parte consiste em execuções rítmicas intrincadas, passagens em ostinato ocasionais e uma vasta gama de dinâmicas (GAUTHREAUX, 1989, p.108). As intervenções do instrumento foram analisadas por David DAVENPORT (1993.a; 1993.b), que sugeriu uma atuação irônica e humorística da caixa como contraponto ao solista, "especialmente nas passagens em que a clarineta começa a levar-se muito a sério" (DAVENPORT, 1993.b, p.52-60). Entretanto, embora a afirmação do crítico musical R. Gregory sobre o Concerto de Nielsen tratarse de um concerto duplo em função da sua atuação 
(Gregory citado por DAVENPORT, 1993.b, p.53) soe claramente infundada, a participação do instrumento é de fato importante e muitos intérpretes optam por incluí-la quando da execução do Concerto, Op.57 com piano. A razão dessa importância está relacionada não à sua execução em particular, mas à forma através da qual ela integra-se ao discurso da clarineta, dando-Ihe maior dramaticidade e intensificando os contrastes entre as passagens mais intensas e complexas com os momentos de maior lirismo.

Todos esses aspectos passam despercebidos a uma análise cujo enfoque seja o conflito tonal entre Fá e Mi maior. Segundo GRIMLEY, os procedimentos utilizados no Concerto, Op.57 baseiam-se antes na condução linear de intervalos que em princípios tonais (GRIMLEY, 2003, p.32). Esses recursos e a forma como o compositor constrói a complexa relação entre solista e orquestra ajudam também a explicar sob uma nova perspectiva o atonalismo encontrado por BINGHAM (BINGHAM, 1990) e indicado no Ex7, bem como a expressão usada por NELSON sobre a "leitura pessoal do termo pelo compositor" (1979a, p.71). A esse respeito, as evidências encontradas não parecem justificar a inclusão do termo atonal ao Concerto, 0p.57; mesmo uma análise mais detalhada na obra de Nielsen parece não sugerir nada mais substancial que simetrias intervalares, transposições locais e funções de retrogradação (Petersen citado por GRIMLEY, 2003, p.32).

Essas análises sugerem que a clarineta solista integrase ao conjunto numa narrativa que é construída por meio de um tema inicial simples, mas que ganha contornos mais amplos à medida que é desenvolvida pelos procedimentos composicionais de Nielsen. Como ele próprio salientou, a "inocência do tema inicial" era uma necessidade para "contrastar com o que viria depois" (Nielsen citado por PETERSEN, 2002, p.xxxviii). Esse contraste é obtido por variações de dinâmicas combinadas com o rigor do contraponto, que somado ao aspecto rítmico que caracteriza o Concerto, $0 p .57$ potencializa os pontos de maior tensão. Sobretudo, as transformações melódicas por meio de variações intervalares parecem ser uma das principais formas de unidade da obra. Nessas transformações, há indícios que sugerem o caráter folclórico, por vezes o caos e mesmo a comicidade por meio de um contorno melódico anguloso tanto nas partes da orquestra quanto na clarineta solista.

A longa jornada desses quatro movimentos ininterruptos encontra uma resolução pouco usual num final que trai o virtuosismo em função de uma nota que é ouvida longamente harmonizando-se com a orquestra (ver Ex4). Na literatura do instrumento, obras assim geralmente dividiram os intérpretes e o público, seja pelo entusiasmo e contraste em relação à tradição de execução, seja por escandalizar ou causar indiferença.

\section{5 - Interpretação e performance}

Desde sua estreia em 1928, o Concerto de Nielsen dividiu opiniões, demonstradas pela polarização da crítica em publicações dinamarquesas da época. Hugo Seliman ressalta que a obra incorpora ao mesmo tempo tanto a natureza selvagem da clarineta quanto o seu lirismo (Seliman citado por PETERSEN, 2002, p.xlii); da mesma forma, William Behrend enfatiza a lógica interna da obra através da insistência das ideias pelo compositor (Behrend citado por PETERSEN, 2002, p.xliii). Mas são, sobretudo, as críticas desfavoráveis que mais se sobressaem.

Em uma longa crítica, o compositor suiço Petersen-Berger considerou o tema do Concerto uma dança dinamarquesa "prevaricante", cujo solo tocado por Oxenvad "cacareja, grita, chora, lamenta e grune", razão pela qual Nielsen termina "confessando-se um cacofonista" (Berger citado por NELSON, 1979a, p.57). 0 jornal dinamarquês Ekstrabladet considerou que a obra era passageira, ou se aquela era a música do futuro, seria de se esperar que as próximas gerações não se sentissem confortáveis nas salas de concerto. Essa opinião é partilhada por uma crítica no jornal Nationaltidende, acrescentando ainda que mesmo um ouvido acostumado à modernidade sente dor ao ouvir o Concerto (PETERSEN, 2002, p.xlii). Some-se a isso o comentário do maestro que regeu sua première, Emil Telmány, considerando a obra "música para outro planeta" (LAWSON, 1997, p.205).

De fato, com uma linguagem inovadora e difícil, o Concerto iria requerer uma interpretação com grande apuro técnico, e pode ter tido sua compreensão prejudicada por uma performance ainda pouco sedimentada, embora a obra tenha sido executada seis vezes durante a vida de Nielsen (PETERSEN, 2002, p.xliii). Ele estava ciente dessa dificuldade, e chegou a negar oportunidades de performance da obra por outros intérpretes, temendo uma leitura inconsistente e prematura (PETERSEN, 2002, p.xlv). Mesmo o clarinetista Aage Oxenvad afirmou que Nielsen devia realmente ser hábil no instrumento, já que teria escolhido sistematicamente as notas mais difíceis de tocar (KETING, 2010). Essa dificuldade parece ter sido determinante para que ele não se sentisse confortável o suficiente para gravá-lo, e nunca o fez (NELSON, 1979a, p.59).

Entretanto, com o tempo as resistências ao Concerto diminuíram e ele passou a ser amplamente difundido. Em 1947, o clarinetista francês Louis CAHUZAC realizou a primeira gravação da obra com a orquestra de Copenhagen pela Columbia (em 78 rotações). A gravação é sem dúvida um registro importante já que a orquestra contava ainda com muitos dos contemporâneos de Nielsen (Oxenvad havia falecido três anos antes), mas CAHUZAC, que contava então já com sessenta e sete anos, apresenta pequenos problemas técnicos, uma sonoridade pouco focada e uma certa descontinuidade entre a parte da orquestra e a da clarineta. Entretanto, é possivel perceber seu fraseado delicado e as nuances de timbre nas passagens mais líricas. 
0 ano de 1965 marcou as comemorações do centenário do nascimento de Nielsen, com uma gravação premiada da sua $3^{a}$ Sinfonia por Leonard Bersntein. A partir de então, o compositor começou a ter maior impacto nas salas de concertos ao redor do mundo e também ser extensivamente gravado (KRABBE, 2012, p.47). Não por acaso, em 1967 o clarinetista Stanley DRUCKER, sob a regência do próprio Bernstein, gravou a obra pela Sony Classical e ao que tudo indica, terminou por popularizar a obra na América do Norte, tornando-se referencial (GIACONA, 2009, 10). No mesmo ano, o clarinetista de jazz Benny G00DMAN teria gravado o Concerto pela RCA e com Morton GOULD na regência, mas ela acabou não sendo tão bem recebida (NELSON, 1979a, 58). Por outro lado, nas décadas seguintes, o Concerto seria gravado por uma série de influentes intérpretes do instrumento, como John Bruce YEH (1985, Centaur), Janet HILTON (1988, Chandos), Richard STOLZMAN (1990, RCA), Philippe CUPER (1992, ADDA), Walter BOEYKENS (1994, Harmonia Mundi), Kevin BANKS (1998, Naxos), Robert PLANE (1999, BBC), Sabine MEYER (2006, EMI), Martin FRÖST (2007, BIS SACD), François BENDA (2008, Genuin), entre outros.

A gravação de BOEYKENS demonstra uma sonoridade plena da clarineta, pela qual o intérprete é conhecido, embora as cadências soem pouco contrastantes, especialmente a primeira, no c.133. Já a de MEYER utiliza um andamento um pouco mais lento em relação à média das demais, o que lhe permite criar alguns contrastes bastante convincentes em termos de andamento. Porém, sua interpretação das cadências apresenta passagens bastante rápidas, mas sem muita continuidade, o que demonstra um virtuosismo que parece, por vezes, desconectar-se da obra. Melhor abordagem parece ser a de BENDA, com uma sonoridade cheia, grande apuro técnico e a interpretação das cadências mais reflexiva e ao mesmo tempo com maior dramaticidade, com grandes acelerandos e diminuendos.

Paradoxalmente, a difusão e popularização da obra foram acompanhadas de um relativo obscurantismo sobre a forma através da qual ela foi concebida na cultura dinamarquesa do começo do século XX. Essa ausência de informações sobre o contexto do Concerto pode estar ligada ao fato do dinamarquês não ser uma língua de domínio comum, mas sobretudo, à uma ênfase muito mais prática do que de contextualização teórica numa cultura onde esses aspectos são de conhecimento geral (NELSON, 2012a).

Durante dois meses do ano de 1979, o clarinetista Eric Nelson estudou no Royal Conservatory de Copenhagem com Tage Scharff, ele próprio um ex-aluno de Oxenvad, e umas das suas principais referências quanto à tradição de execução do Concerto. Ele corrobora sua experiência de campo como entrevistas e aulas com Tage Scharff, além de analisar a correspondência entre compositor e intérprete e dados analítico-estruturais presentes na obra de Nielsen. Assim, no artigo publicado na revista The Clarinet (NELSON, 1987), enunciando a tradição de performance dinamarquesa propriamente dita, o autor deixa claro o desdém ou indiferença que encontrou entre clarinetistas dinamarqueses por interpretações não escandinavas do Concerto como a de Stanley DRUCKER e mesmo Louis CAHUZAC.

Por outro lado, o autor cita três gravações que considera representantes dessa tradição de performance (NELSON, 2012a). Entre elas estão a do suiço Kjell-Ingle STENVENSSON (1975, EMI), a de Håkan ROSEGREN (1991, Sony), mas, sobretudo, a de Niels THOMSEN (1990, Chandos). A de STENVENSSON tem grande apuro técnico, e apresenta acima de tudo uma liberdade maior nas cadências do Concerto, com um diálogo bastante efetivo nas passagens entre solista e orquestra. Por outro lado, na gravação de THOMSEN é notório o contraste em relação às gravações como a de MEYER, BOEYKENS e CAHUZAC em termos de caráter da obra. Embora não tenha a mesma fluidez técnica que a de BENDA no geral, a interpretação conecta-se bem com a orquestra formando um todo coeso. Além disso, a sonoridade do instrumento soa por vezes extremamente agressiva nos registros extremos do instrumento, e o intérprete vale-se de pequenos rubatos em diversas situações. Especialmente no tocante à expressividade nas cadências, o tratamento dado é bastante enérgico (sobretudo na última), com grandes expansões de dinâmica que beiram o limite das possibilidades do instrumento, além de usar pausas mais longas entrecortando as retomadas da melodia. $\mathrm{Na}$ versão de THOMSEN, o Concerto assume uma postura mais dramática que explora os extremos do instrumento em variações de andamento e dinâmica, mas que ainda assim soam convincentes no contexto da obra.

Em suas observações sobre a partitura de Oxenvad, NELSON relata uma série de anotações encontradas, com expressões como "feio!", "maníaco depressivo", "improvisacional", "contemplativo", "satânico", "brilhante", "humorístico", entre outras (1987, p.35). Além disso, nos comentários de Scharff sobre a obra, é possivel perceber uma ênfase na construção intervalar da melodia, muito mais que do virtuosismo em si. Segundo Scharff, a única passagem que considera virtuosística é a escala ascendente em meio à última cadência (c.519, sétima e oitava linha da partitura da clarineta), com as tercinas a seguir marcadas por ele como "satanicamente lento" (NELSON, 1987, p.34).

Discussões interpretativas sobre o Concerto podem ser encontradas no trabalho de GIACONA (2009), que analisou quatro gravações da obra e entrevistou os intérpretes, sendo eles os norte-americanos Stanley Drucker, Elsa Ludewig-Verdehre, John Bruce Yeh, e o escandinavo Hågan Rosengren. Numa discussão sobre a relevância da obra, praticamente todos os intérpretes concordam que o Concerto, Op.57 de Nielsen pode ser equiparado ao de Mozart na literatura da clarineta (GIACONA, 2009, p.143). Além disso, ela explora as alternativas propostas pelos intérpretes baseadas em suas concepções pessoais para 
resolver os problemas técnicos, incluindo as mudanças de articulação, diferentes posições e digitações no instrumento, bem como a interpretação das cadências.

Nesse sentido, é digna de nota a diferença de abordagens do Concerto pelos intérpretes; profundamente influenciado pela gravação de Cahuzac (GIACONA, 2009, p.20), Drucker é por sua vez uma clara influência nos outros dois intérpretes norte-americanos, sobretudo em Yeh. Essa influência fica mais evidente ao comparar a concepção da obra dos três intérpretes com a do escandinavo Rosengren. Nascido em Stocolmo e criado ao sul da Suécia, Rosengren familiarizouse desde cedo com a cultura dinamarquesa e sua tradição de performance. Assim, enquanto Drucker defende uma postura de fidelidade à partitura impressa, Rosenberg a interpreta buscando compreender as motivações por trás das marcações ${ }^{7}$ (GIACONA, 2009, p.84). Ele também fala sobre como a obra de Nielsen transformou-se em sua fase final e como o Concerto se encaixa nessa perspectiva, especialmente com a construção de diferentes áreas tonais. Sobretudo, ele considera que a obra não é virtuosística já que sempre associou sua dificuldade técnica à expressão musical. Para Rosengren, a dificuldade técnica não é grande se comparada ao desafio musical de interpretá-la em seu devido contexto (GIACONA, 2009, p.83).

Outros trabalhos sobre a performance do Concerto de Nielsen ainda incluem o de LANZ (1989), que analisa juntamente com outros dois concertos de Nielsen, o para violino e o para flauta. Além dele também Ann Marie Bingham analisou a interpretação das cadências do Concerto por vários intérpretes, e incluiu o seu próprio trabalho de preparação da obra com as anotações de Tage Scharff, com quem também estudou (BINGHAM, 1990).

Dentre as gravações pesquisadas, é relevante que os intérpretes familiarizados com a tradição cultural da Escandinávia demonstrem certos aspectos em comum, como a busca por maior contraste e expressividade, além de uma abordagem mais livre das cadências. Essa expressividade é claramente diferenciada na forma de interpretar indicações como o ad libitum depois da escala ascendente na última cadência, no c.519 (conforme indicado no Ex12).
Nesse trecho selecionado no Ex12, foi possível observar que enquanto intérpretes como CAHUZAC, DRUCKER e CUPER tendem a interpretá-lo de forma mais literal, respeitando a proporção da notação, MEYER, BOEYKENS, mas sobretudo STENVENSSON e THOMSEN permitem-se uma liberdade maior, variando o ritmo mais livremente e com acentos mais pronunciados.

Por outro lado, através da importante gravação de CAHUZAC com a Royal Copenhagen Orchestra, é possivel perceber uma acentuação sutil da orquestra na nota mais longa do tema inicial (destacado no Ex11.e), diferente da maioria das gravações modernas que tendem a executála mais como a nossa compreensão moderna do tenuto. Essa acentuação discreta mas presente em toda a obra proporcionou uma nítida diferença na interpretação da orquestra, que contando com músicos que integravam o meio social do compositor, permitem a suposição do quanto das sutilezas dessa natureza na tradição de performance original da obra já não são mais ouvidas.

Não obstante a diferença de abordagem entre as performances e as pesquisas que a suportam, há uma intenção geral de dar subsidios ao instrumentista numa tentativa de contornar o que PINO chama de "dez páginas de uma sólida e bestial dificuldade" (PINO, 1980, p.264). Dentro do contexto da sua composição, entretanto, as discussões sobre a demanda técnica assumem um aspecto secundário, abrindo caminho para considerações sobre uma melhor compreensão do caráter que a obra incorpora.

\section{6 - Considerações finais}

De uma forma geral, o que se percebe numa leitura mais detalhada desses aspectos é que a maneira precisa através da qual uma obra influente como o Concerto para Clarineta, Op.57 foi composta encontra sua razão de ser na forma como Nielsen expressa-se dentro da cultura dinamarquesa de sua época. Assim, a sua densidade de textura, bem como a dificuldade técnica da qual o compositor estava consciente e sublinhada já por Oxenvad, além de sentida por muitos ouvintes e intérpretes ao longo do tempo, são na verdade a estrutura de superfície da sua sólida técnica de composição. Nesse

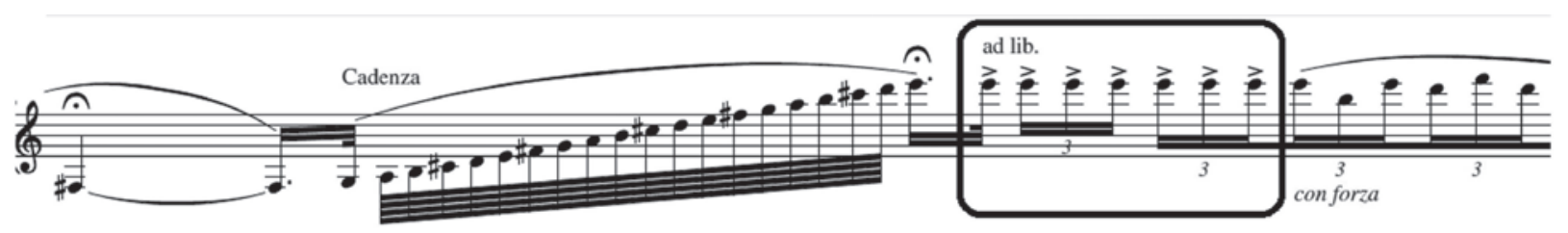

Ex.12 - Excerto da cadência no c.519 do Concerto para Clarineta, Op.57 de Carl Nielsen, com destaque para o trecho indicado como ad libitum. 
mesmo lastro, alguns autores consideram o seu Concerto para Clarineta não só como a sua maior conquista, mas também um marco na literatura da clarineta (Maegard citado por NELSON, 1979a, p.53).

Combinar os diferentes problemas de digitação, articulação e dinâmica com um caráter que oscila de "humorístico" a "maníaco-depressivo" dentro de uma narrativa ininterrupta de aproximadamente vinte $e$ cinco minutos de música foi de fato uma abordagem inovadora. Nesse sentido, o Concerto de Nielsen difere de outras obras de seus contemporâneos, especialmente pela envergadura estrutural. No Concerto, a estrutura ampla dá conta de uma narrativa essencialmente complexa. 0 tema dançante da abertura se transforma durante a obra, emergindo aqui e ali melódica e ritmicamente modificado, ganhando cada vez mais diferentes contornos expressivos.

Carl Nielsen tinha uma visão particular sobre certos aspectos da sua música, e sua obra já era conhecida por seus contemporâneos por ser excessivamente difícil. Avesso ao que chamou de sentimentalismo superficial e virtuosismo sem sentido, mas também às correntes modernas representadas por Schoenberg e Stravinsky, o nacionalismo de Nielsen talvez o tenha alinhado mais com Bartok. Entretanto, Nielsen construiu uma sólida técnica de composição por conta própria, conjugando os procedimentos polifônicos que admirava em Palestrina e Bach com uma orquestração aparentemente rude $e_{1}$ por vezes, brutal, como demonstrada no Concerto, Op.57.

Ao utilizar uma dança folclórica como fio condutor, Nielsen cria uma narrativa densa, cuja dramaticidade fica evidente no diálogo entre o solista e a orquestra, pontuados percussivamente pela inclusão da caixa clara. Sua instrumentação vale-se de uma linguagem difícil e uma abordagem individual dos instrumentos, que explora limites de tessitura e dinâmica, enfatizando a construção melódico-intervalar e a complexidade rítmica, muito mais que a questão tonal da obra, cujas evidências demonstraram ser secundária.
De uma forma geral, a aceitação e popularização do Concerto no decorrer do tempo foi paradoxal, na medida em que desconsideraram aspectos do contexto onde a obra foi realizada, o que pode ser constatado na indiferença dos clarinetistas dinamarqueses com os intérpretes não escandinavos observada por Eric Nelson. Por outro lado, o trabalho de gravação por intérpretes como o francês Louis Cahuzac e o norte-americano Stanley Drucker foi um dos principais meios de divulgação e propagação da obra, influenciando decisivamente na sua inclusão no repertório de concerto da clarineta.

Dentre os trabalhos pesquisados, ficou claro que as questões técnicas devem ser entendidas como parte de um processo maior que busque incorporar à performance as significações históricas e analíticas necessárias ao equilibrio da complexa relação entre solista e orquestra. Por isso mesmo, tal qual salientou o clarinetista Hågan Rosengren, a obra é melhor entendida em seu contexto, evitando uma interpretação que preze por um virtuosismo puro e simples sobre o caráter da obra.

Esse tipo de abordagem é comumente manifestada na falsa relação em medir o nível de um instrumentista por ter ou não estudado o Concerto, 0p.57 de Nielsen (PINO, 1980, p.265). Além de propagar uma visão um tanto superficial da obra e da performance em si, esse tipo de relação pode gerar uma frustração nos estudantes que se julgam inaptos a interpretá-lo naquele momento adequadamente, incitando-os a crer que não serão bons instrumentistas sem fazê-lo. Isso, claro, não é verdade.

Uma perspectiva mais razoável é que a obra necessita realmente de uma boa base técnica para ser interpretada, mas que essa exigência vem em função da expressão de um caráter complexo da cultura dinamarquesa; inicialmente campesino, ele se transforma rapidamente e assume contornos mais densos. Escolher expressar-se ou não através dessa obra e seu caráter é uma opção do instrumentista, e por si mesmo, nada diz sobre o nível técnico de quem quer que seja. 


\section{Referências}

ARAÚJO, João Paulo de. Laboratório de Composição para Clarineta Solo: Uma experiência entre intérpretes e estudantes de composição. Salvador: Universidade Federal da Bahia, 2006 (Dissertação de Mestrado).

BINGHAM, Ann Marie. Carl Nielsen's Koncert for Klarinet og Orkester, opus 57 (1928): a performance guide. Lexington: University of Kentucky, 1990 (Tese de Doutorado).

BRYANT, Michael. The Clarinet on Record. In: LAWSON, C. J. (Ed.) The Cambridge Companion to the Clarinet. Cambridge: Cambridge University Press. Pg. 199-212.

BURHOLDER, J. Peter. A Simple Model for Associative Musical Meaning. IN: Amén, Byron e Pearsall, Edward (Ed.). Approaches to Meaning in Music. 76-106. Bloomington e Indianapolis: Indiana University Press, 2006.

BURROWS, John \&t WIFFEN, Charles (ed). Música Clássica. Tradução de André Telles. Rio de Janeiro: Jorge Zahar Editor Ltda, 2007.

BUTLER, Christopher. Innovation and the avant-garde, 1900-20. In: COOK, Nicholas \& POPLE, ANTHONY (ed.). The Cambridge History of Twentieth-Century Music. Cambridge: Cambridge University Press, 2004. Pg. 69-89.

DAVENPORT, David. Carl Nielsen's Use of the Snare Drum, 1916-1928 (Part I). In: Percussive Notes: Journal of the Percussive Arts Society, 31, N. 4, 1993a. Pg. 56-59.

Carl Nielsen's Clarinet Concerto:Specific Interpretation Approach (Part II). IN: Percussive Notes: Journal of the Percussive Arts Society, 31, N. 5, 1993b. Pg. 52-60.

FELUMG, Svend Christian. De gamle bloesere - og Carl Nielsen. In: Dansk Musik Tidsskrift. V.33, N.2. 1958. Disponivel em <http://dvm.nu/periodical/dmt/dmt_1958/dmt_1958_02/de-gamle-blaesere-og-carl-nielsen/>. Acessado em 20/03/2012.

GAUTHREAUX, Guy Gregoire II. Orchestral Snare Drum Performance: An Historical Study. Baton Rouge: Louisiana State University and Agricultural and Mechanical College. 1989 (Tese de Doutorado).

GIACONA, Christina. A Study of Comparative Interpretations by Stanley Drucker, Elsa Ludewig-Verdehr, Håkan Rosengren and John Bruce Yeh of the Clarinet Concerto by Carl Nielsen. Norman: University of Oklahoma, 2009 (Tese de Doutorado).

GREEN, Burdette \& BUTLER, David. From Acustics to Tonpsychologie. IN: Christenssen, Thomas (ed). The Cambridge History of Western Music Theory. Cambridge University Press: Cambridge, 2006.

GRIMLEY, Daniel. Analytical and Aesthetic Issues in Carl Nielsen's Concerto for Clarinet and Orchestra. In: KRABBE, Niels (ed.). Carl Nielsen Studies. V.1, 2003. Pg. 27-41.

KETTING, Kund. Art and Consciousness. IN: Carl Nielsen Society. Disponivel em < http://carlnielsen.dk/pages/biography/ art-and-consciousness.php>. Acessado em 02/12/2010.

KRABBE, Niels. A Survey of the Written Reception of Carl Nielsen, 1931-2006. In: Notes - Quartely Journal of the Music Library Association. V.64. N.1., 2007. Disponivel em < http://muse.jhu.edu/journals/notes/toc/not64.1.html>, acessado em 26/03/2012.

KRABBE, Niels. Carl Nielsen, Ebbe Hamerik and the First Symphony. In: KRABBE, Niels (Ed.). Carl Nielsen Studies. V.1, 2003. Pg.102-123.

LABOURIĖSSE, Marilia. Interpretação Musical: a dimensão recriadora da "comunicação" poética. Goiânia: Anablume, 2007.

LANZ, Christopher Charles. The Concerti of Carl Nielsen. Standford: Standford University, 1989 (Tese de Doutorado).

LAWSON, Jack. Carl Nielsen. Londres: Phaidon, 1997.

MAEGARD, Jan. An Outline of Danish Musical History. IN: Samfundet til Udgivelse of Danish Musik Katalog. Copenhagen: Dan Fog-Olsen, 1956. Pg 8-13.

MEYER, Torben. Carl Nielsen: Kunstneren og Mennesket. 2 V. Copenhagen: Nyt Nordisk Forlag, 1947.

MONROE, Douglas. Conflict and Meaning in Carl Nielsen's Concerto for Clarinet an Orchestra, Op.57 (1928). Athens: Ohio State University, 2008 (Tese de Doutorado).

NATIIEZ, Jean-Jacques. O Combate entre Cronos e Orfeu: ensaios de semiologia musical aplicada. Tradução de Luiz Paulo Sampaio. São Paulo: Via Lettera, 2005.

NELSON, Eric. The Nielsen Concerto and Aage Oxenvad. Disponivel em <http://www.woodwind.org/clarinet/Study/Nielsen. html>. Acessado em 10/03/2012 (2012a).

Performances Notes on Carl Nielsen's Koncert For Klarinet Og Orkester, Op.57. Disponivel em http://www. woodwind.org/clarinet/Study/NielsenNotes.html\#page_10. Acessado em 02/03/2012 (2012b).

The Danish Performance Tradition in Carl Nielsen's Koncert for Klarinet og Orkester, Op.57 (1928). IN: The Clarinet, 14, N.2, 1987. Pg 30-35.

Carl Nielsen's Koncert for Klarinet og Orkester, Op.57 (1928) within the Context of Danish Musical History. Denton: North Texas State University, 1979a (Dissertação de Mestrado).

Entrevista com o crítico musical dinamarquês Robert Naur. Material não publicado enviado pelo autor,

$1979 b$. 
OXENVAD, Aage. Entrevista concedida ao jornal dinamarquês Berlingske Tidende, datado de 10/10/1928. Tradução do dinamarquês enviada ao autor por Eric Nelson.

PETERSEN, Elly Bruunshuus. Prefácio da Edição do Concerto para Clarineta, Op.57 de Carl Nielsen. Copenhagen: Editora Wilhelm Hansen, 2002. Disponivel em <http://www.kb.dk/en/kb/nb/mta/cnu/download.html>. Acessado em 02/12/2010.

PETERSEN, Elly Bruunshuus \& PETERSEN, Kirsten Flensborg (Ed.). Koncert for Klarinet og Orkester, Op.57. Edition Wilhelm Hansen: Copenhagen, 2002.

PETERSEN, Kirsten Flensborg. Carl Nielsen's Flute Concert: Form and revision of the ending. In: KRABBE, Niels (Ed.). Carl Nielsen Studies. V.2, 2005. Pg.196-225.

PINO, David. The Clarinet and Clarinet Playing. New York: Charles Scribner's Sons, 1980.

ROSENBERG, Herbert. The Concertos. In: Carl Nielsen Centenary Essays. Ed. Jürgen Balzer. Transc. Holzer Norgaard e N. Bugge Hansen. Londres: Dobson, 1966. Pg. 47-55.

SIMPSON, Robert. Carl Nielsen - Symphonist. London : Kahn \&t Averill, 1986.

SCHOUSBOE, Torben (ed.), Carl Nielsen, Dagbøger og brevveksling med Anne Marie Carl-Nielsen, Copenhagen: Carlsbergfondets, 1983.

WATERHOUSE, John C. G. Nielsen Reconsidered 2. IN: The Musical Times, V.106, N.1469, 1965. Pg. 515-517. Disponível em $<$ http://www.jstor.org/stable/950198> Acessado em 20/02/11.

WESTON, Pamela. More Clarinet Virtuosi of the Past. Londres: Panda Press, 1982.

WHITE, Tyler G. 'The Music's Proper Domain': form, motive and tonality in Carl Nielsen's Symphony no. 4 Op.29 (The Inextinguishable). Ithaca: Cornell University, 1991 (Tese de Doutorado).

\section{Discografia}

BANKS, Kevin e BAKELS, Kees (dir.). Nielsen. Bournemouth Symphony Orchestra. Naxos, 1998.

BENDA, François e BENDA, Christian (dir.). Clarinet and Orchestra: works of Rossini, Debussy, Busoni and Nielsen. Slowakische Philharmonie. Genuin Classics, 2008.

BOEYKENS, Walter e CAEYERS, Jan (dir.). Carl Nielsen: Clarinet Concerto/Pan \& Syrinx/Amor \&t Digteren. Beethoven Academie Orchestra. Harmonia Mundi, 1994.

CAHUZAC, Louis e FRANDSEN (dir.). Nielsen Clarinet Concert, Op.57. Royal Copenhagen Orchestra. LP em 78 rotações.1947.

CUPER, Philippe e SCHNITZLER, Claude (dir.). Copland/Françaix/Nielsen: Concertos for Clarinet \&t Orchestra. L'Orchestre de Bretagne. Accord, 1993.

DRUCKER, Stanley e BERNSTEIN, Leonard (dir.). Concerto for Clarinet and Orchestra, by Carl Nielsen. New York Philharmonic. Sony Classical, 1967.

FRÖST, Martin e VÄNSKÄ, Osmo (dir.). Nielsen \& Aho: clarinet concertos. Lahti Symphony Orchestra. Bis, 2007.

GOODMAN, Benny e GOULD, Morton (dir.). Nielsen/Clarinet Concerto -Symphony N² "The Four Temperaments". Chicago Symphony. RCA, 1967.

HILTON, Janet e BAMERT, Matthias (dir.). Copland - Lutoslawsky - Nielsen. Royal Scottish National Orchestra. Chandos, 1988.

MEYER, Sabine e RATTLE, Simon (dir.). Nielsen: clarinet and flute Concertos-Wind Quintet. Berliner Philharmoniker. EMI Classics, 2006.

PLANE, Robert e OTAKA, Tadaaki (dir.). Nielsen. BBC National Orchestra of Wales. BBC, 1999.

ROSEGREN, Håkan e SALONEN, Esa-Pekka (dir.). Concerto for Clarinet and Orchestra, by Carl Nielsen. Swedish Radio Symphony Orchestra. Sony BMG Masterworks, 1993.

STENVENSSON, Kjell-Inge e BLOMSTED, Herbert (dir.). 20 $0^{\text {th }}$ Century Classics: Carl Nielsen. The Danish Radio Symphony Orchestra. EMI, 2008.

STOLTZMAN, Richard e SMITH, Lawrence Leighton (dir.). Richard Stoltzman: Lutoslawski, Nielsen, Prokofiev. Warsaw Philharmonic Orchestra. RCA, 1990.

THOMSEN, Niels e SCHONWANDT, Michael (dir.). Nielsen: violin, flute and clarinet Concertos. Danish National Symphony Orchestra. Chandos, 1990.

YEH, John Bruce e KOBER, Dieter, (dir.) Concerto for Clarinet and Orchestra, by Carl Nielsen. Chicago Chamber Orchestra. Centaur Records, 1987. 


\section{Notas}

1 Também chamada de embocadura de duplo lábio, onde os lábios superior e inferior recobrem os dentes em contato com a boquilha e palheta (PINO, 1980, p.59). Informação obtida de acordo com entrevista concedida por Robert Naum a Eric Nelson (NELSON, 1979b).

2 Última cadência do Concerto, no trecho correspondente à página 8, linha 8 da edição impressa. Como a edição da Samfundet til Udgivelse af Dansk Musik não apresenta numeração de compassos, eles foram incluídos para fins de referência dos trechos citados nesse trabalho. Inicialmente, os critérios para a numeração não levariam em conta os compassos indicados por linhas pontilhadas no fim da primeira longa cadência da clarineta no compasso 133, exatamente por estar incluso ainda na referida cadência. Essa decisão seria a mais adequada em termos de coerência e é suportada por numeração equivalente em trabalhos de análise como o recentemente publicado por Daniel GRIMLEY (GRIMLEY, 2003). Entretanto, como a nova edição da Wilhelm Hansen também citada nesse trabalho resolve incluí-los como compassos numerados (PETERSEN \& PETERSEN, 2002, p. 201), a numeração utilizada passou a seguir essa última por questões de praticidade. Assim, o compasso após a cadência acima citada será o número 143, ao invés de 134, e assim por diante.

3 Cujo prefácio e grade orquestral estão disponíveis para download aqui <http://www.kb.dk/en/kb/nb/mta/cnu/download.html>.

4 Maestro que regeu a première do Concerto e genro de Nielsen.

5 Na referência original, "stamp-kick-stamp" (NELSON, 1987, p.32).

6 A numeração que o autor utiliza é diferente da adotada nesse trabalho. Assim optou-se pela mudança nos números de compasso visando a sua padronização. Para mais detalhes, ver nota 2.

7 Segundo ele, as marcações de tenuto devem ser interpretadas de forma similar a um acento na música vocal (GIACONA, 2009, 84).

Vinícius de Sousa Fraga é Bacharel em Clarineta pela Universidade Federal de Santa Maria-RS (UFSM) sob a orientação do Prof. Dr. Guilherme Sampaio Garbosa e Mestre em Execução - clarineta pela Universidade Federal da Bahia (UFBA) sob a orientação do Prof. Dr. Pedro Robatto. Sua dissertação discutiu aspectos da interpretação da Fantasia Sul América para clarineta solo de Cláudio Santoro. Atualmente, é Doutorando em Execução Musical pela mesma instituição. 